\title{
Prevotella amnii sp. nov., isolated from human amniotic fluid
}

\author{
Paul A. Lawson, ${ }^{1}$ Edward Moore ${ }^{2}$ and Enevold Falsen ${ }^{2}$ \\ ${ }^{1}$ Department of Botany and Microbiology, University of Oklahoma, Norman, OK 73019-0245, USA \\ ${ }^{2}$ Culture Collection, Department of Clinical Bacteriology, University of Göteborg, \\ SE-413 46 Göteborg, Sweden
}

\begin{abstract}
Two Gram-negative, anaerobic, non-spore-forming, rod-shaped organisms were isolated from human amniotic fluid. Based on morphological and biochemical criteria, the strains were tentatively identified as Bacteroidaceae but they did not appear to correspond to any recognized species of this family. Comparative 16S rRNA gene sequencing studies showed the strains were highly related to each other and confirmed their placement in the genus Prevotella, but sequence divergence values of $>4 \%$ with reference Prevotella species demonstrated that the organisms from human clinical sources represent a novel species. Phylogenetic analysis revealed the novel organism to be most closely related to Prevotella bivia, an organism frequently associated with pelvic inflammatory diseases. The major long-chain cellular fatty acids of the novel species consist of iso- $C_{14: 0}$, anteiso- $C_{15: 0}$, iso- $C_{15: 0}, C_{16: 0}$, iso- $C_{16: 0}$ and iso-3-OH- $C_{17: 0}$. Based on biochemical criteria and phylogenetic considerations, it is proposed that the unknown isolates from human amniotic fluid be assigned to a new species of the genus Prevotella, as Prevotella amnii sp. nov. The type strain of Prevotella amnii is CCUG $53648^{\top}\left(=\mathrm{JCM} 14753^{\top}\right)$.
\end{abstract}

The genus Prevotella includes moderately saccharolytic, bile-sensitive species formally belonging to the genus Bacteroides (Shah \& Collins, 1990). Many species of Prevotella have been isolated from human sources often associated with the oral cavity; indeed of the recently described species all have been isolated from this location (Downes et al., 2005; Sakamoto et al., 2004, 2005a, b). However, a number of species have been isolated from both healthy and infected tissues of the pelvic region, including the genitourinary tract, vagina and cervix (Brook \& Frazier, 1997; Fredricks et al., 2005; Hyman et al., 2005; Mikamo et al., 1999; Puapermpoonsiri et al., 1997). During a continuing study of Gram-negative anaerobic rods, two strains were deposited with the Culture Collection of the University of Göteborg (CCUG), Sweden. Based on the results of a polyphasic taxonomic study, it is proposed that the isolates be assigned to the genus Prevotella, as Prevotella amnii sp. nov.

Isolate CCUG $53648^{\mathrm{T}}$ was recovered from the amniotic fluid of a 29-year-old female in 1999, the fluid was described as turbid and ill smelling; CCUG 43050 was isolated from a 26-year-old female in 2006, again from amniotic fluid. The unidentified organisms were cultured on Columbia agar supplemented with $5 \%$ defibrinated horse blood (Oxoid) at $37{ }^{\circ} \mathrm{C}$, in an atmosphere of $85 \%$ nitrogen, $10 \%$ carbon dioxide and $5 \%$ hydrogen. The

The GenBank/EMBL/DDBJ accession number for the 16S rRNA gene sequence of strain CCUG $53648^{\top}$ is AM422125. strains were characterized biochemically by using a combination of conventional tests as described in the VPI Anaerobe Laboratory Manual (Holdeman et al., 1977), and API rapid ID32AN and API ZYM systems according to the manufacturer's instructions. Fermentation tests were performed using pre-reduced, anaerobically sterilized (PRAS) peptone-yeast (PY)-sugar broth tubes. All biochemical tests were performed in duplicate. Long-chain cellular fatty acids were extracted and analysed by GC (MIDI Sherlock) as described by Pot et al. (1994). End products of glucose metabolism were determined by GLC. 16S rRNA gene fragments were generated by PCR using universal primers and the amplified products were purified by using a QIAquick PCR purification kit and sequenced directly using primers to conserved regions of the $16 \mathrm{~S}$ rRNA gene. Sequencing was performed using a PRISM Taq Dye-deoxy Terminator Cycle Sequencing Kit (Applied Biosystems) and an automatic DNA sequencer (model 373A; Applied Biosystems). The closest known relatives of the new isolates were determined by performing database searches using the FASTA3 search program (www.ebi.ac.uk/ fasta33/nucleotide.html; Pearson \& Lipman, 1988). These sequences and those of other known related strains were retrieved from GenBank and aligned with the newly determined sequences using the program SEQTOOLS (www.seqtools.dk). The resulting multiple sequence alignment was corrected manually using the program GENEDOC (Nicholas et al., 1997) and a phylogenetic tree was constructed according to the neighbour-joining method 
(Saitou \& Nei, 1987) with the programs SEQTOOLS and TREEVIEW (Page, 1996). The stability of the groupings was estimated by bootstrap analysis (1000 replications) using the same programs.

The two isolates originating from human amniotic fluid were anaerobic, non-spore-forming, non-motile, Gramnegative rods. Typical cells were $0.8-3.0 \times 0.5-1.5 \mu \mathrm{m}$. Colonies on blood agar plates after $48 \mathrm{~h}$ of incubation at $37{ }^{\circ} \mathrm{C}$ under anaerobic conditions were white, smooth, glistening with an entire edge and less than $1 \mathrm{~mm}$ in diameter. Cells were still viable after $6 \mathrm{~h}$ when left in air, and the catalase reaction was negative for the same period. No growth was observed in $\mathrm{CO}_{2}$. Using the API Rapid ID32AN test system the unknown clinical isolates were positive for $N$-acetyl- $\beta$-D-glucosaminidase, alkaline phosphatase, alanine arylamidase, $\beta$-galactosidase, phospho-6$\beta$-galactosidase, $\alpha$-glucosidase, glutamyl-glutamic acid arylamidase and leucyl-glycine arylamidase. All other reactions in the API Rapid ID32AN test system were negative. Employing the API ZYM test kit, positive reactions were obtained for $N$-acetyl- $\beta$-D-glucosaminidase, $N$-AS-BI-phosphohydrolase, alkaline phosphatase, acid phosphatase, $\alpha$-glucosidase and $\beta$-glucosidase. All other tests were negative using the API ZYM gallery. Indole was not produced and nitrate was not reduced. The major end products of glucose metabolism were acetic and succinic acids, with minor amounts of isovaleric, isocaproic and lactic acids also detected. The quantitative fatty acid profile of CCUG $53648^{\mathrm{T}}$ consisted of $\mathrm{C}_{13: 1}(0.4 \%), \mathrm{C}_{14: 0}(0.9 \%)$, iso- $\mathrm{C}_{14: 0} \quad(5.6 \%), \mathrm{C}_{15: 0} \quad(0.3 \%)$, iso- $\mathrm{C}_{15: 0} \quad(16.4 \%)$, anteiso- $\mathrm{C}_{15: 0}(32.3 \%)$, iso-3-OH-C ${ }_{15: 0}(0.9 \%), \mathrm{C}_{16: 0}$ $(6.4 \%)$, iso- $\mathrm{C}_{16: 0}(9.7 \%), 3 \mathrm{OH}-\mathrm{C}_{16: 0}(2.0 \%)$, iso- $\mathrm{C}_{17: 0}$ $(3.4 \%)$, anteiso- $\mathrm{C}_{17: 0}(2.9 \%)$, iso-3-OH-C $17: 0(10.3 \%)$, $2-\mathrm{OH}-\mathrm{C}_{17: 0}(1.1 \%), \mathrm{C}_{18: 0}(1.8 \%)$ and $\mathrm{C}_{18: 1 \omega 9 c}(2.9 \%)$.

To determine the phylogenetic affinities between the isolates and to other species, the 16S rRNA gene sequences were amplified by PCR and sequenced. The two isolates CCUG $53648^{\mathrm{T}}$ and CCUG 43050 were found to be genetically highly related to each other, displaying $99.5 \%$ $16 \mathrm{~S}$ rRNA gene sequence similarity. Treeing analysis revealed the isolates were members of the BacteroidesPrevotella-Porphyromonas rRNA supercluster of organisms (data not shown), demonstrating a specific affinity with members of the genus Prevotella. The phylogenetic position of CCUG $53648^{\mathrm{T}}$ using a reduced dataset is shown in Fig. 1. Treeing analysis clearly showed that this unknown bacterium represents a new subline within the genus Prevotella, sharing a branching node with Prevotella bivia (95.3\% 16S rRNA gene sequence similarity) supported by a $100 \%$ bootstrap value. These two species were peripheral to a subcluster of organisms that included Prevotella disiens, Prevotella intermedia, Prevotella nigrescens and

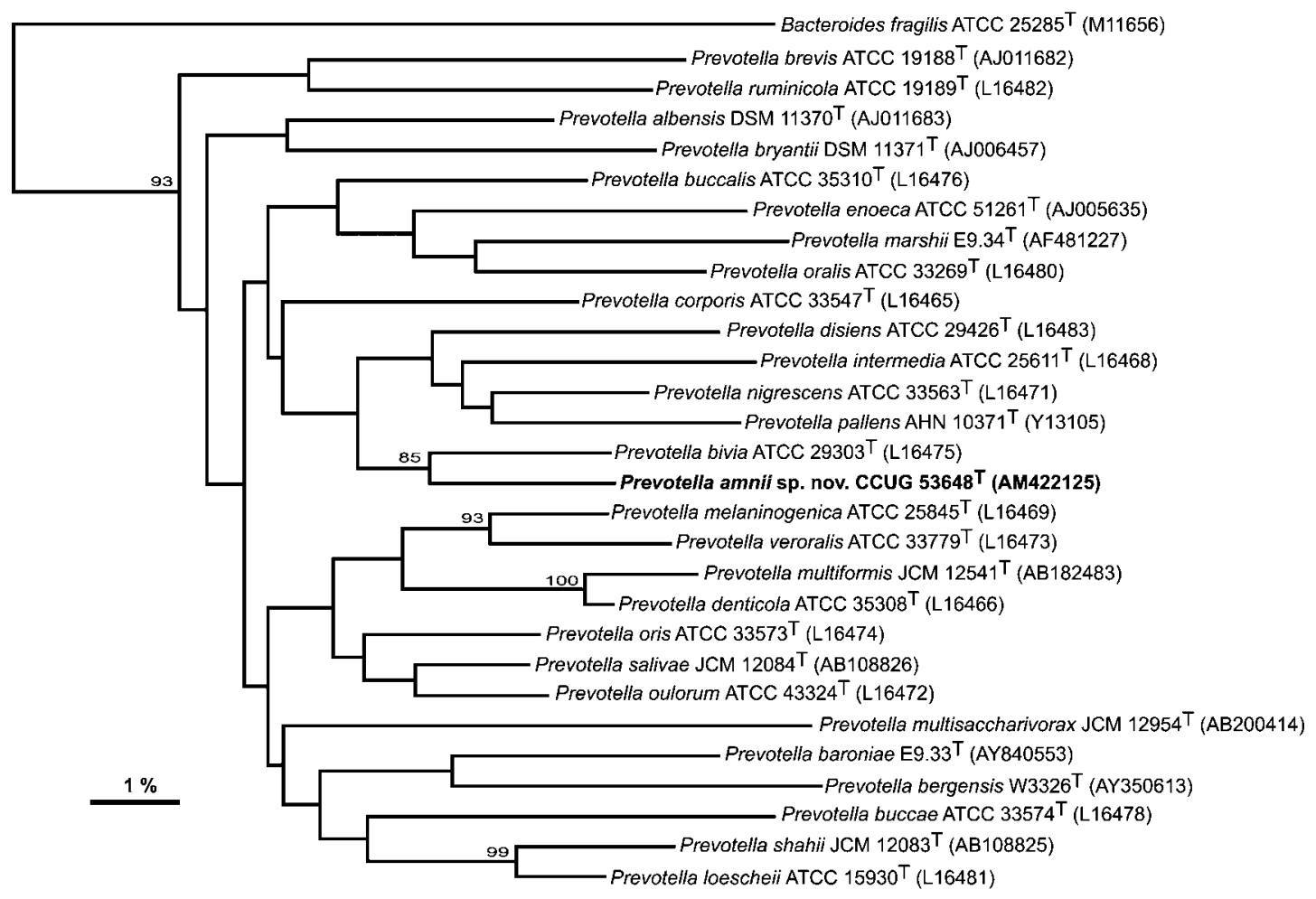

Fig. 1. Unrooted tree showing the phylogenetic inter-relationships of Prevotella amnii sp. nov. amongst its nearest relatives. The tree was constructed using the neighbour-joining method and is based on a comparison of $1330 \mathrm{nt}$. Bootstrap values, each expressed as a percentage of 1000 replications, are given at branching points. Bar, $1 \%$ sequence divergence. 
Prevotella pallens, exhibiting lower levels of sequence similarity. There is no precise correlation between percentage 16S rRNA sequence divergence and species delineation, but it is generally recognized that divergence values of $3 \%$ or more are significant (Stackebrandt \& Goebel, 1994). Support for the distinctiveness of the unknown bacterium isolated from amniotic fluid was also very evident from phenotypic analyses. Tests which are useful in distinguishing Prevotella amnii from some other related Prevotella species are shown in Table 1. Our analysis demonstrated that the closest phylogenetic relative was Prevotella bivia, an organism originally isolated from the endometrium and frequently recovered from patients with pelvic inflammatory diseases (Brook \& Frazier, 1997; Puapermpoonsiri et al., 1997), including its recovery from amniotic fluid with preterm premature rupture of the associated membranes (Mikamo et al., 1999). In addition, sequence database searches revealed that a number of studies using culture-independent $16 \mathrm{~S}$ rRNA gene sequencing strategies investigating the vaginal microflora of healthy women isolated a number of clonal sequences with almost $100 \%$ similarity to our two isolates. It is therefore likely that the organism reported here is present in healthy women, but in certain circumstances can be enriched for and involved in certain disease processes and should be regarded as an emerging opportunistic pathogen. Furthermore, it is likely that some isolates formally associated with pelvic diseases and presumptively identified as Prevotella bivia were in fact strains of the novel organism reported in this article. In particular, the unknown bacterium can be readily distinguished from Prevotella bivia by the production of phospho- 6 - $\beta$-galactosidase and its inability to produce $\alpha$-fucosidase and glutamyl-glutamic

Table 1. Biochemical characteristics useful in differentiating Prevotella amnii sp. nov. from type strains of some other closely related members of the genus Prevotella

Taxa: 1, Prevotella amnii CCUG $53048^{\mathrm{T}}$; 2, Prevotella bivia CCUG $9557^{\mathrm{T}} ; 3$, Prevotella disiens CCUG $9558^{\mathrm{T}} ; 4$, Prevotella intermedia CCUG $24041^{\mathrm{T}} ; 5$, Prevotella nigrescens CCUG $9560^{\mathrm{T}} ; 6$, Prevotella pallens CCUG $39484^{\mathrm{T}}$. All data are taken from Rapid ID32AN tests performed at CCUG (www.ccug.se). +, Positive; -, negative; w, weak.

\begin{tabular}{|c|c|c|c|c|c|c|}
\hline Characteristic & 1 & 2 & 3 & 4 & 5 & 6 \\
\hline$N$-Acetyl- $\beta$-D-glucosaminidase & + & + & - & - & - & - \\
\hline Arginine arylamidase & - & - & + & + & $\mathrm{w}$ & + \\
\hline$\alpha$-Fucosidase & - & + & - & + & + & + \\
\hline Phospho-6- $\beta$-galactosidase & + & - & - & - & - & - \\
\hline$\beta$-Galactosidase & + & + & - & - & - & - \\
\hline $\begin{array}{l}\text { Glutamyl-glutamic acid } \\
\text { arylamidase }\end{array}$ & - & + & - & - & - & - \\
\hline Indole & - & - & + & - & $\mathrm{w}$ & + \\
\hline Raffinose & - & - & - & - & - & + \\
\hline
\end{tabular}

acid arylamidase. We therefore consider the formal description of this novel species and the biochemical criteria will aid its identification and will facilitate its recognition in the routine laboratory to distinguish it from Prevotella bivia and thereby permit the recovery of additional strains. Furthermore, for unequivocal identification, 16S rRNA gene sequence analysis is recommended and is now being increasingly incorporated into the clinical laboratory setting. Based on the presented phenotypic and phylogenetic evidence, we consider the two unidentified isolates recovered from human amniotic fluid be assigned to the genus Prevotella, as Prevotella amnii sp. nov.

\section{Description of Prevotella amnii sp. nov.}

Prevotella amnii (am'ni.i. Gr. n. amnion, inner membrane surrounding the fetus; N.L. gen. n. amnii, of the amnion, pertaining to the amniotic fluid from which the organism was first isolated).

Cells consist of Gram-negative rods that are anaerobic, non-motile and non-spore-forming. Typical cells are $0.8-$ $3.0 \times 0.5-1.5 \mu \mathrm{m}$. Colonies on blood agar plates after $48 \mathrm{~h}$ of incubation at $37{ }^{\circ} \mathrm{C}$ under anaerobic conditions are white, smooth, glistening with an entire edge and less then $1 \mathrm{~mm}$ in diameter. Cells are still viable after $6 \mathrm{~h}$ when left in air. Using the API Rapid ID32AN test system, positive reactions are produced with $N$-acetyl- $\beta$-D-glucosaminidase, alkaline phosphatase, alanine arylamidase, phospho-6- $\beta$ galactosidase, $\beta$-galactosidase, $\alpha$-glucosidase, glutamyl-glutamic acid arylamidase and leucyl glycine arylamidase. Using the API ZYM test kit, positive reactions are obtained for $N$-acetyl- $\beta$-D-glucosaminidase, $N$-AS-BI-phosphohydrolase, alkaline phosphatase, acid phosphatase, $\alpha$-glucosidase and $\beta$-glucosidase. Indole is not produced and nitrate is not reduced. Aesculin is hydrolysed but gelatin is not. Glucose, lactose and maltose are fermented, but cellobiose, fructose, inositol, mannitol, melibiose, rhamnose, salicin, sucrose and trehalose are not. The major end products of glucose metabolism are acetic and succinic acids. The major long-chain cellular fatty acids consist of iso- $\mathrm{C}_{14: 0}$, iso- $\mathrm{C}_{15: 0}$, anteiso- $\mathrm{C}_{15: 0}, \mathrm{C}_{16: 0}$, iso- $\mathrm{C}_{16: 0}$ and iso- $3 \mathrm{OH}-\mathrm{C}_{17: 0}$.

The type strain, CCUG $53648^{\mathrm{T}}\left(=\mathrm{JCM} 14753^{\mathrm{T}}\right)$, was isolated from human amniotic fluid.

\section{Acknowledgements}

We thank J. Euzéby for the naming of the novel species, Sofia Wernersson for DNA sequencing, and Elisabeth Inganäs and Maria Ohlén for excellent technical assistance. We also thank the depositors of the strain to the CCUG, Inger Mattsby-Baltzer (Department of Clinical Bacteriology, University of Göteborg) and S. Kawash (PHLS, Eastern Hospital, Göteborg).

\section{References}

Brook, I. \& Frazier, E. H. (1997). The aerobic and anaerobic bacteriology of perirectal abscesses. J Clin Microbiol 35, 2974-2976. 
Downes, J., Sutcliffe, I., Tanner, A. C. R. \& Wade, W. G. (2005). Prevotella marshii sp. nov. and Prevotella baroniae sp. nov., isolated from the human oral cavity. Int J Syst Evol Microbiol 55, 1551-1555.

Fredricks, D. N., Fiedler, T. L. \& Marrazzo, J. M. (2005). Molecular identification of bacteria associated with bacterial vaginosis. $N$ Engl J Med 353, 1899-1911.

Holdeman, L. V., Cato, E. P. \& Moore, W. E. C. (1977). Anaerobe Laboratory Manual, 4th edn. Blacksburg, VA: Virginia Polytechnic Institute and State University.

Hyman, R. W., Fukushima, M., Diamond, L., Kumm, J., Giudice, L. C. \& Davis, R. W. (2005). Microbes on the human vaginal epithelium. Proc Natl Acad Sci U S A 102, 7952-7957.

Mikamo, H., Sato, Y., Hayasaki, Y., Kawazoe, K., Izumi, K., Satoh, M., Kai, J. \& Tamaya, T. (1999). In vitro bactericidal activities of antimicrobial agents and morphologic changes on Prevotella bivia. Chemotherapy 45, 342-348.

Nicholas, K. B., Nicholas, H. B., Jr \& Deerfield, D. W., II (1997). GeneDoc: analysis and visualization of genetic variation. EMBnet News 4 (2), 1-4. www.embnet.org/files/shared/embnetnews/embnet_ news_4_2.pdf

Page, R. D. M. (1996). TreeView: an application to display phylogenetic trees on a personal computer. Comput Appl Biosci 12, 357-358.

Pearson, W. R. \& Lipman, D. J. (1988). Improved tools for biological sequence comparison. Proc Natl Acad Sci U S A 85, 2444-2448.
Pot, B., Vandamme, P. \& Kersters, K. (1994). Analysis of electrophoretic whole-organism protein fingerprints. In Chemical Methods in Prokaryotic Systematics, pp. 493-521. Edited by M. Goodfellow \& A. G. O’Donnell. Chichester: Wiley.

Puapermpoonsiri, S., Watanabe, K., Kato, N. \& Ueno, K. (1997). In vitro activities of 10 antimicrobial agents against bacterial vaginosisassociated anaerobic isolates from pregnant Japanese and Thai women. Antimicrob Agents Chemother 41, 2297-2299.

Saitou, N. \& Nei, M. (1987). The neighbour-joining method: a new method for reconstructing phylogenetic trees. Mol Biol Evol 4, 406-425.

Sakamoto, M., Suzuki, M., Huang, Y., Umeda, M., Ishikawa, I. \& Benno, Y. (2004). Prevotella shahii sp. nov. and Prevotella salivae sp. nov., isolated from the human oral cavity. Int J Syst Evol Microbiol 54, 877-883.

Sakamoto, M., Huang, Y., Umeda, M., Ishikawa, I. \& Benno, Y. (2005a). Prevotella multiformis sp. nov., isolated from human subgingival plaque. Int J Syst Evol Microbiol 55, 815-819.

Sakamoto, M., Umeda, M., Ishikawa, I. \& Benno, Y. (2005b). Prevotella multisaccharivorax sp. nov., isolated from human subgingival plaque. Int J Syst Evol Microbiol 55, 1839-1843.

Shah, H. N. \& Collins, M. D. (1990). Prevotella, a new genus to include Bacteroides melaninogenicus and related species formerly classified in the genus Bacteroides. Int J Syst Bacteriol 40, 205-208.

Stackebrandt, E. \& Goebel, B. M. (1994). Taxonomic note: a place for DNA-DNA reassociation and $16 \mathrm{~S}$ rDNA sequence analysis in the present species definition in bacteriology. Int J Syst Bacteriol 44, 846-849. 